\title{
Parents' physical victimization in childhood and current risk of child maltreatment: The mediator role of psychosomatic symptoms
}

\author{
Diogo Lamela*, Bárbara Figueiredo \\ School of Psychology, University of Minho, Portugal
}

\section{A R T I C L E I N F O}

Article history:

Received 1 March 2013

Received in revised form 1 April 2013

Accepted 2 April 2013

\section{Keywords:}

Child victimization

Psychosomatic symptomatology

Child maltreatment

Parenting

\begin{abstract}
A B S T R A C T
Objective: To test the potential mediation effect of psychosomatic symptoms on the relationship between parents' history of childhood physical victimization and current risk for child physical maltreatment. Methods: Data from the Portuguese National Representative Study of Psychosocial Context of Child Abuse and Neglect were used. Nine-hundred and twenty-four parents completed the Childhood History Questionnaire, the Psychosomatic Scale of the Brief Symptom Inventory, and the Child Abuse Potential Inventory.

Results: Mediation analysis revealed that the total effect of the childhood physical victimization on child maltreatment risk was significant. The results showed that the direct effect from the parents' history of childhood physical victimization to their current maltreatment risk was still significant once parents' psychosomatic symptoms were added to the model, indicating that the increase in psychosomatic symptomatology mediated in part the increase of parents' current child maltreatment risk.

Discussion: The mediation analysis showed parents' psychosomatic symptomatology as a causal pathway through which parents' childhood history of physical victimization exerts its effect on increased of child maltreatment risk. Somatization-related alterations in stress and emotional regulation are discussed as potential theoretical explanation of our findings. A cumulative risk perspective is also discussed in order to elucidate about the mechanisms that contribute for the intergenerational continuity of child physical maltreatment.
\end{abstract}

(C) 2013 Elsevier Inc. All rights reserved.

\section{Introduction}

Past empirical research has demonstrated that child physical maltreatment is a major risk factor for negative developmental and health outcomes during the life-span. Besides the physical injuries, physically maltreated children exhibit a heightened risk of cognitive and academic functioning problems [1], more prevalence of internalizing and externalizing disorders [2], more difficulties in social functioning [3] and a higher incidence of substance abuse [4], high-risk sexual behaviors, and delinquency [5] during adolescence and youth. In addition, adults with history of physical maltreatment in childhood report higher risk of mental health disorders [6,7], chronic physical health problems [8,9], alcohol abuse [10], suffering and perpetrating intimate partner violence [11] and also greater likelihood of physically maltreating their offspring [12].

Some scholars have theoretically outlined that parents with experiences of exposure to physical maltreatment and harsh parenting practices are more likely to engage in the use of physical punishment strategies as parents [13]. Despite the fact that previous literature reviews highlighted that the intergenerational research of child maltreatment should be interpreted with some caution [14], a consistent growing body of recent

\footnotetext{
* Corresponding author at: School of Psychology, University of Minho, Campus de Gualtar, 4710-057 Braga, Portugal. Tel.: + 351916983336.

E-mail address: dlamela@ese.ipvc.pt (D. Lamela).
}

literature has supported, however, that parents' childhood history of physical victimization is one of the most robust parent-related predictors of actual child physical maltreatment [15-18]. Similar findings were found in the investigations that examined the offspring physical maltreatment risk [19-22]. However, these previous findings that measured physical maltreatment risk rather than effective maltreatment were drawn from studies conducted with small or at-risk, and/or non-representative samples [14]. These sampling limitations should therefore be considered as a caveat of existing literature.

Additionally, some empirical research has focused on the risk mechanisms that contribute to the intergenerational continuity of child physical maltreatment. Depression [23], dissociation [24], mental health problems [25], trauma symptoms [19], and social information processing bias [16] have been identified as psychological mechanisms through which parents' experience of physical victimization in childhood exerts effect on current risk of perpetrating physical abusive behaviors in their offspring. Surprisingly, despite the high prevalence of history of childhood maltreatment among the adults with somatization disorders [26-28], to our knowledge, no previous empirical study explored parents' psychosomatic symptoms as a mediator mechanism between these two variables. Moreover, only one investigation has examined the relationship between parents' psychosomatic symptoms and their risk of physical maltreatment of offspring [29], which can be considered as a limitation of the existing literature. Therefore, in light of the consistent body of research associating the experience of maltreatment in childhood 
with psychosomatic symptoms/disorders in adulthood [28,30-33], as well as linking parents' psychosomatic symptoms with their risk of child physical maltreatment [29], it is plausible to hypothesize that parents' psychosomatic symptoms may function as a mediator link in the association between parents' history of physical victimization and parents' risk of physical maltreatment.

In summary, taking into account these previous findings, it can be assumed that parents' psychosomatic symptoms are one potential risk mechanism in the intergenerational transmission of child maltreatment, since parents with a history of physical victimization in childhood are more likely to experience psychosomatic symptoms and they also might report a heightened risk of physical maltreatment. More concretely, current psychosomatic symptoms might increase the risk of perpetration of physical maltreatment of the offspring in parents that reported physical victimization in childhood.

Therefore, using data from a community survey with Portuguese parents, the aims of the current investigation are twofold. First, we investigated intergenerational transmission of physical maltreatment risk, by examining the direct association between parents' history of physical maltreatment victimization in childhood and current risk of physical maltreatment. We expected parent's history of maltreatment to be positively related with their current risk of physically maltreating their children. Additionally, this study extends previous research by also testing the potential mediation effect of psychosomatic symptoms on the relationship between parents' history of childhood physical victimization and a current risk for child physical maltreatment. We expected, firstly, that parents' current psychosomatic symptoms were predicted by parents' history of physical maltreatment as well as a predicted parents' risk of physical maltreatment of their offspring; additionally, we expected that high levels of psychosomatic symptoms might partially explain the intergenerational continuity of risk of physical maltreatment. In the current study, sociodemographic covariates that theoretically and empirically have been associated with physical maltreatment victimization and/or perpetration risk were included in the testing of direct and indirect effects.

\section{Method}

\section{Participants}

Participants were 924 parents or primary caregivers that participated in the National Representative Study of Psychosocial Context of Child Abuse and Neglect in Portugal. Parents ranged in age from 22 to 66 and had on average 1.92 children $(S D=.91$, range $=1$ to 9 ). Parents' socio-demographic characteristics are summarized in Table 1. A comparison to the national population statistics for marital status, education level, income and number of children in the year that participants' data were collected revealed that the current sample is representative of the Portuguese population.

\section{Measures}

\section{Parents' history of physical victimization in childhood}

Parents' childhood experience of physical maltreatment was assessed through the Childhood History Questionnaire [34]. The CHQ presented nine physically maltreatment events (e.g., whipping, slapping/kicking, bruises/welts, bone fractures) and participants were asked to rate the frequency of occurrence of each one of them, prior to age 13 . The responses to the frequency of occurrence of each physically abusive event were made on a 5 -point scale ( 0 , never to 4 , very often). Responses to the items were summed to compute a frequency of physically maltreatment events index (possible total scores range from 0 to 36). Higher scores reflect more frequent physical maltreatment victimization in childhood perpetrated by the participant's parent or primary caregiver. The Portuguese version of $\mathrm{CHQ}$ exhibited adequate psychometric
Table 1

Description of sample $(N=924), n(\%)$ for categorical variables and $M(S D)$ for continuous variables

\begin{tabular}{|c|c|c|c|}
\hline & \multicolumn{2}{|c|}{ Value } & \multirow[t]{2}{*}{$M(S D)$} \\
\hline & $n$ & $\%$ & \\
\hline Age & & & $37.12(6.26)$ \\
\hline \multicolumn{4}{|l|}{ Gender } \\
\hline Female & 507 & 54.9 & \\
\hline Male & 417 & 45.1 & \\
\hline \multicolumn{4}{|l|}{ Marital status } \\
\hline Married/cohabiting & 850 & 92.0 & \\
\hline Divorced/widow/single & 74 & 8.0 & \\
\hline \multicolumn{4}{|l|}{ Education } \\
\hline$\leq 12$ years & 710 & 76.8 & \\
\hline College degrees & 214 & 23.2 & \\
\hline \multicolumn{4}{|l|}{ Employment status $^{\mathrm{a}}$} \\
\hline Employed & 738 & 82.8 & \\
\hline Unemployed & 65 & 7.3 & \\
\hline Retired/other & 88 & 9.9 & \\
\hline \multicolumn{4}{|l|}{ Family income } \\
\hline$\leq 3.5$ national minimum wage & 522 & 56.5 & \\
\hline$\geq 3.6$ national minimum wage & 402 & 43.5 & \\
\hline \multicolumn{4}{|l|}{ Parents' household composition } \\
\hline With spouse and with child(ren) & 836 & 90.4 & \\
\hline Alone with children & 57 & 6.2 & \\
\hline Other & 31 & 3.4 & \\
\hline $\mathrm{CHQ}$ & & & $2.13(2.58)$ \\
\hline CAPI & & & $22.85(12.61)$ \\
\hline SomBSI & & & 3.55 (3.99) \\
\hline
\end{tabular}

Note. $\mathrm{CHQ}=$ Childhood History Questionnaire; CAPI = Child Abuse Potential Inventory; SomBSI $=$ Somatization Scale of the Brief Symptom Inventory.

$$
\text { a } N=891 \text {. }
$$

properties [35]. In the current sample, internal consistency was very $\operatorname{good}($ Cronbach's $\alpha=.81$ ).

\section{Child physical maltreatment risk}

The abuse scale of the Child Abuse Potential Inventory (CAPI) [36] was used to assess parents' attitudes and practices regarding physical forms of discipline and abuse. The CAPI abuse scale examines distress, rigidity, unhappiness, problems with the child and the self, problems with the family and with others, and problems of others (e.g., 'Children should never disobey', 'A good child keeps his toys and clothes neat and orderly'). The items are answered in a forced-choice format $(0$, no or 1 , yes). The Portuguese version of CAPI abuse scale, which is comprised by 74 items, showed excellent psychometric properties and also revealed high discriminant power between abusive parents and community parents [37]. Total scores on CAPI abuse scale range from 0 to 74 (unit scoring procedure was applied), with higher scores reflecting more risk of child physical abuse. The internal consistency (Cronbach's $\alpha$ ) of the CAPI for the current sample was .88 .

\section{Psychosomatic symptoms}

The somatization scale of the Brief Symptom Inventory (SomBSI) [38] was administered to assess parents' psychosomatic symptoms. Based on BSI theoretical rationale, this scale assesses the psychological distress arising from a perception of bodily dysfunction, focusing mainly in complaints on respiratory, cardiovascular and gastrointestinal systems with strong autonomic mediation (e.g., 'Trouble in getting your breath', 'Faintness or dizziness'). Parents answered to the 7 items of BSI somatization scale based on their level of distress associated with each symptom over the previous week. The items are answered on a 5 -point Likert-scale $(0$, not at all to 4 , extremely). Total scores on BSI somatization scale range from 0 to 28 . Higher scores correspond to more psychosomatic symptomatology. Scale's reliability to screening psychosomatic symptomatology is consistently demonstrated in previous research [39]. The Portuguese version of the BSI somatization subscale 
revealed good psychometric properties [40]. For the current sample, Cronbach's alpha was .81.

\section{Procedures}

Participants were a subset of parents in the National Representative Study of Psychosocial Context of Child Abuse and Neglect in Portugal (PCCANP). Participants were mothers and fathers of children randomly selected in five public elementary schools of Northern Portugal (for a detailed description about sample selection procedures see Figueiredo et al. [35]). All parents whose children attended the selected schools were contacted in the year 2000. Regional education authorities (DREN, Direcção Regional da Educação do Norte) provided ethical approval for the current research. All parents were informed about the research aims and ethic procedures in meeting sessions with research team members and teachers. Afterwards, assessment protocols and letters of informed consent in sealed envelopes were provided by the teachers to the children who in turn handed them to their parents. From 1021 parents and primary caregivers who consented to participate in the community school-based survey, 924 parents (533 mothers and 438 fathers) completed and returned successfully the assessment protocols in sealed envelopes to the teachers by their children (response rate $=90.5 \%$ ).

\section{Statistical procedure}

Initially, a linear regression was conducted to test the direct association between parents' history of physical victimization during childhood and their current physical maltreatment risk. Subsequently, a mediation analysis was conducted to test the mediation effect of depression symptoms on the association between history of physical maltreatment victimization and current physical maltreatment risk. Mediation was conducted by examining the statistical significance of the associations between the independent variable and mediator ( $a$ path), between the mediator and dependent variable controlling for the independent variable ( $b$ path), and, finally, by computing $a b$ cross-product. Testing $a b$ cross-product is established as the most accurate and reliable approach to test mediation [41], since it allows calculating the significance of the difference between the total effect ( $c$ path) and the direct effect ( $c$ ' path), which represent the impact of the independent variable on the dependent variable adjusting for the effect of the mediator.

In the last two decades, Baron and Kenny's causal steps approach [42] and Sobel test [43] have been regularly applied in biomedical and social sciences to conduct mediation analysis. Nevertheless, these approaches present several limitations [44] and bootstrapping techniques are being recommended to test mediation $[45,46]$. Bootstrapping statistic is a nonparametric method which allows to examine the statistical significance of paths $a$ and $b$, and the cross product of the path $a b$ without assuming the normal distribution of the indirect effects [44]. Prior simulation studies demonstrated that bootstrapping is a more powerful and accurate method than causal steps and the Sobel test in the estimation of mediation effect [47]. For the current set of analysis, a macro for SPSS created by Preacher and Hayes [46] was employed to test our hypothesized mediation model. Using the Preacher and Hayes method [46], the examination of the indirect effect comprised four steps: (1) 20000 bootstrap samples were randomly generated (random sampling with replacement procedure) from the original data set (924 participants), (2) based on this bootstrap sample, the paths $a$ and $b$ and indirect effect $(a b)$ estimates were computed, (3) this procedure was repeated 20000 times and 20000 estimates of the indirect effect of interest were attained, and (4) the mean of these 20000 estimates of the indirect effect was computed and if the $95 \%$ bias corrected and accelerated confidence intervals $(95 \% \mathrm{CI})$ of the indirect effects do not contain zero, then the indirect effect was statistically significant. This macro also allows for the adjustment of all paths for the potential impact of covariates on the mediation model.
Results

Correlational findings

Zero-order correlations between parents' sociodemographic variables, parents' history of childhood physical maltreatment victimization, parents' child physical maltreatment risk and parents' psychosomatic symptoms are presented in Table 2. Considering the study's main variables, parents' history of childhood physical maltreatment victimization was significantly and positively associated with their current levels of child physical maltreatment risk. Parents' history of maltreatment victimization was also significantly and positively related to parents' current psychosomatic symptoms. Finally, a significant and positive association between parents' current psychosomatic symptoms and their child physical maltreatment risk was found.

Considering the significant associations in the past empirical research [15,48,49], as well as the amount of significant associations in the current study between parents sociodemographic variables and parents' childhood physical maltreatment victimization (independent variable) and/or parents' current child physical maltreatment risk (dependent variable), all further analysis included parents' age, gender, marital status, education, family income and number of children as covariates.

Direct association between parents' physical maltreatment victimization in childhood and offspring physical maltreatment risk

Results of hierarchical regression are presented in Table 3. The findings revealed that parents' history of childhood physical maltreatment victimization and their risk of child physical maltreatment were significantly and positively associated. More specifically, after accounting for the effect of the covariables, parents' history of physical maltreatment victimization (entered in Step 2) predicted child physical maltreatment risk, in which, whether parents' sociodemographic covariables are held constant, as parents' childhood victimization increases by one unit, parents' current risk of physically maltreating their offspring increases by 0.86 unit. The final regression model accounted for $22 \%$ of variance on parents' child physical maltreatment risk $(F=36.68, d f=7,917, p=.001)$.

\section{Mediation effect of the psychosomatic symptoms}

Parents' psychosomatic symptoms were tested as mediator of the association between parents' history of physical victimization in childhood and their current risk of physical maltreatment of the offspring (Fig. 1). Mediation analysis revealed that the total effect of parents' history of physical victimization on their current physical maltreatment risk was significant $(B=.80, S E=.14, p=.001$ ). After controlling the effect of the covariates (parents' gender, age, marital status, education, family income and number of children), parents' history of physical victimization in childhood predicted parents' psychosomatic symptoms $(B=.33$, $S E=.04, p=.001)$. In turn, parents' psychosomatic symptoms predicted parents' current risk of physically maltreating their offspring $(B=1.60, S E=0.09, p=.001)$. The examination of the indirect effect ( $a b$ path) revealed a significant mediation (Indirect effect $=0.54$; $95 \% \mathrm{CI}$ for bias correct indirect effect: Lower Lever $=0.36$, Upper Level $=0.74$ ), in which the association between parents' history of physical victimization and parents' risk of physical maltreatment was mediated by an increase in parents' psychosomatic symptoms. The direct effect of childhood physical victimization to parents' current maltreatment risk increase also remained significant once parents' psychosomatic symptoms were added to the model $(B=0.27, S E=.13, p=.03)$, indicating that the increase in psychosomatic symptomatology mediated, in part, the influence of parents' history of physical victimization on parents' current physical maltreatment risk increase. Overall, $42 \%$ of physical maltreatment risk variance was accounted by the entire model.

\section{Discussion}

Previous research has demonstrated that parents' childhood history of maltreatment is a robust precedent risk factor for parents' child maltreatment $[15,16]$. However, the mere identification of parents' childhood victimization history is uninformative about the nature of the risk process. Considering the empirical evidence linking parents' maltreatment history and psychosomatic disorders/conditions [31,33], as well as the single study that found that parents' with higher psychosomatic symptoms exhibited a significant greater likelihood of child physical maltreatment [29], psychosomatic symptoms were hypothesized as a possible causal risk mechanism variable between parents' childhood physical maltreatment history and their current risk of offspring physical maltreatment. The current study is the first investigation that examined the mediating effect of psychosomatic symptoms, which represent an innovative feature of the current research.

Overall, our findings seemed to provide empirical evidence to the positive association between parents' history of physical maltreatment victimization and their current risk of physical maltreatment of the offspring. In line with previous epidemiological, cross-sectional and longitudinal researches, our results suggest that parents who reported to be 
Table 2

Zero-correlations between parents' sociodemographics, childhood physical victimization, risk of child maltreatment, and psychosomatic symptoms

\begin{tabular}{|c|c|c|c|c|c|c|c|c|c|}
\hline & 1. & 2. & 3. & 4. & 5. & 6. & 7. & 8. & 9. \\
\hline 1. Parents' gender & - & & & & & & & & \\
\hline 2. Parents' age & $.23^{* *}$ & - & & & & & & & \\
\hline 3. Marital status & $-.14^{* *}$ & -.06 & - & & & & & & \\
\hline 4. Parents' education & -.06 & $.11^{* *}$ & -.06 & - & & & & & \\
\hline 5. Family income & $.07^{*}$ & $.13^{* *}$ & $-.13^{* *}$ & $.51^{* *}$ & - & & & & \\
\hline 6. Number of children & -.01 & $.37^{* *}$ & .03 & .04 & -.05 & - & & & \\
\hline 7. Childhood physical victimization (CHQ) & .04 & -.03 & .02 & .02 & .003 & .06 & - & & \\
\hline 8. Child physical maltreatment risk (CAPI) & $-.17^{* *}$ & .06 & $.21^{\text {** }}$ & $-.21^{* *}$ & $-.28^{* *}$ & $.26^{* *}$ & $.16^{* *}$ & - & \\
\hline 9. Psychosomatic symptoms (SomBSI) & $-.24^{* *}$ & .003 & .06 & $-.15^{* *}$ & $-.17^{* *}$ & $.11^{* *}$ & $.21^{* *}$ & $.58^{* *}$ & - \\
\hline
\end{tabular}

Note. $\mathrm{CHQ}=$ Childhood History Questionnaire; CAPI = Child Abuse Potential Inventory; SomBSI = Somatization Scale of the Brief Symptom Inventory.

$* p<.05$.

$* * \quad p<.001$.

more frequent victims of physical maltreatment behaviors perpetrated by a primary caregiver in childhood exhibited greater risk of physical maltreatment of their offspring. For example, Kim [17], using data from a US representative longitudinal study, found that parents who retrospectively report physical maltreatment victimization in childhood are 5 times as likely to exhibit physical maltreatment parenting practices than those who were not physically abused in childhood.

Our results also corroborated previous literature that examined the link between parents' history of physical victimization and their current physical maltreatment risk (not the effective maltreatment behaviors) [20-22]. In addition, our study extends the literature by supporting previous findings using a large representative sample of parents, since past studies that analyzed this association between parents' history of physical victimization and their current risk of physical maltreatment were conducted in small, high-risk and unrepresentative samples [14].

In line with previous research [50], an association between child physical abuse and adults' psychosomatic symptoms was found. Additionally, the current investigation also demonstrated that parents' psychosomatic symptomatology was a causal pathway through which parents' childhood history of physical victimization exerts part of its effect on an increase of child maltreatment risk. This is a new finding in literature. Therefore, the mechanisms through which psychosomatic symptoms may lead to child physical maltreatment need to be uncovered. For instance, somatization-related alterations in psychobiological systems of stress regulation, as well as the difficulties in emotion modulation, may explain the mediating effect of psychosomatic symptoms in the intergeneration continuity of child physical maltreatment. More specifically, early psychosocial stress, such as exposition to physical victimization in childhood, may have the potential to induce chronic and

Table 3

Results of the hierarchical regression analysis

\begin{tabular}{lllll}
\hline Steps & $B(S E)$ & $\beta$ & $R^{2}$ & $\Delta R^{2}$ \\
\hline Step 1 & & & \\
Parents' gender & $-3.97(0.79)$ & $-.16^{* * * *}$ & & \\
Parents' age & $0.09(0.07)$ & .05 & & \\
Marital status & $-4.08(1.45)$ & $.15^{* * *}$ & & \\
Parents' education & $-4.32(1.04)$ & $-.15^{* * *}$ & & \\
Family income & $3.10(0.45)$ & $-.17^{* * *}$ & & \\
Number of children & $35.50^{* * *}$ & $.23^{* * *}$ & & \\
$F(d f=6,918)$ & & & & \\
Step 2 & $0.86(0.14)$ & $.18^{* * *}$ & & .03 \\
Childhood physical & $35.34^{* * *}$ & & .22 & \\
$\quad$ victimization (CHQ) & & & \\
$\Delta F(d f=1,917)$ &
\end{tabular}

Note. $\mathrm{CHQ}=$ Childhood History Questionnaire.

$* * * \quad p<.001$. dysfunctional under- or overactivity of the psychobiological systems responsible for regulation and adaptation to stress. Some studies have suggested that the dysregulation stress-adaptation systems may contribute to intensified symptom experience and pain perception. Elevated levels of psychosomatic symptoms may reflect the dysfunction to regulate parenting-related stress that, in turn, may be associated to a higher probability of a parent to engage in harsh parenting and abusive behaviors to cope with offspring behaviors [51]. Additionally, psychosomatic symptoms may also be associated to impairments in the functional emotion regulation [52-54] and difficulties in emotion expression and reduced empathy behaviors have been found in parents in risk of physically maltreating their children [55-57].

Showing that the association between parents' history of physical victimization and physical maltreatment risk operated only in part through parents' psychosomatic symptoms, our findings gave evidence that parents' psychosomatic symptoms were only one of the mechanisms that contribute to an intergenerational transmission of child maltreatment. Past research has demonstrated that an increased risk of child physical maltreatment is predicted by parents' individual and family variables. More specifically, parents' risk of physical maltreatment has been associated with higher levels of depression and psychopathological symptomatology [15], social isolation [16], higher life stress [58], low marital satisfaction [15], and alcohol and substance abuse [59]. It is plausible to hypothesize that, given its developmental origins [60,61], psychosomatic symptomatology may function as a precedent mechanism for developing and maintaining some of these risk factors associated with a heightened likelihood of physical maltreatment. Some empirical evidence supported this assumption. For example, in longitudinal investigations, psychosomatic symptoms were found as a significant predictor of subsequent diagnosis of depression [62,63], whereas physical maltreatment in childhood seemed to predict somatization among patients diagnosed with a major depression disorder [64]. In addition, considering the partial mediation effect of psychosomatic symptomatology, it is possible to speculate that the interplay of parents' psychosomatic symptoms and the other risk factors may operate in a cumulative fashion. Future research should examine longitudinally how psychosomatic symptoms may cumulatively interact with other proximal and distal risk factors to predict child maltreatment. This interactive approach will allow testing not only the significance of risk variables with main effects (direct and mediating effects) but also moderating variables that qualify these main effects [65]. Since our findings revealed that some of the variables included as covariates in the model showed a significant effect on parents' risk of child physical maltreatment, further studies should delineate a conceptual model in which these covariates were conceptualized as moderators with the potential to affect the direction and strength of the association between parents' history of maltreatment and their risk of maltreatment.

The results of this research should be interpreted bearing some limitations in mind. Firstly, parents' history of physical maltreatment 


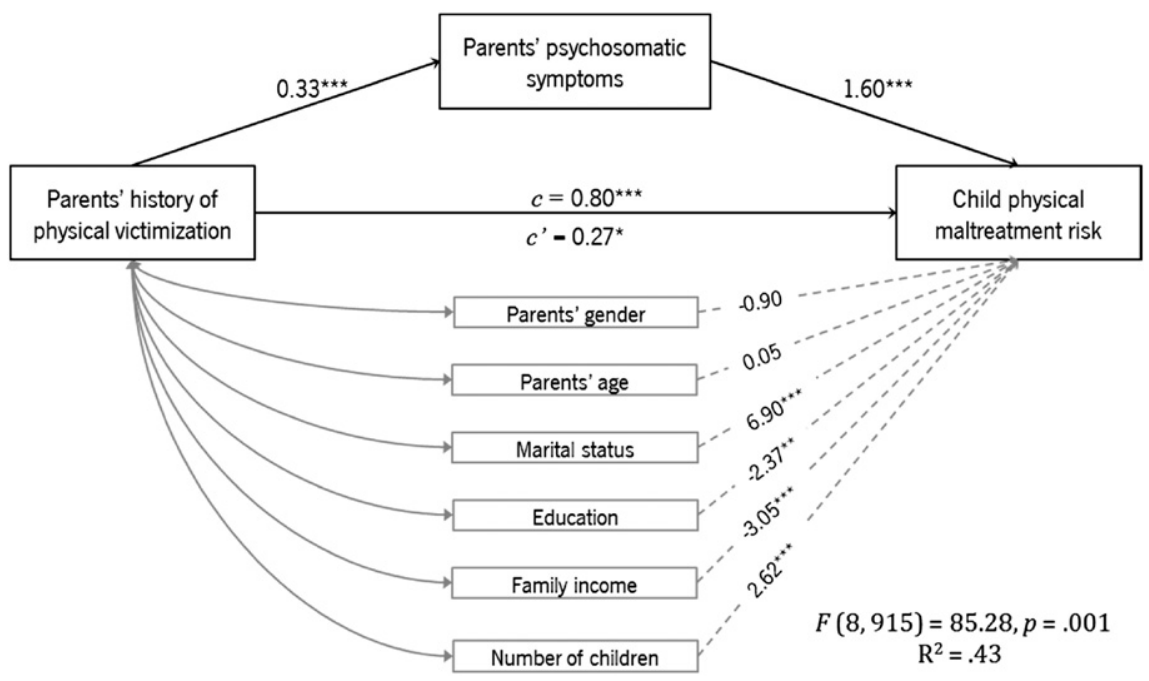

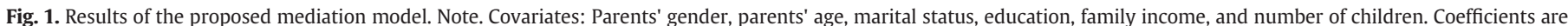
unstandardized parameter estimates. ${ }^{*} p=.03 .{ }^{* *} p=.01 .{ }^{* * *} p=.001$.

victimization in childhood was assessed by a retrospective self-report questionnaire. Retrospective recall of physical victimization in childhood may involve substantial rate of false negatives and considerable measurement errors. Despite the fact that some research has demonstrated that such limitations were not sufficiently great to invalidate retrospective studies of childhood adversities [66-68], some caution should be taken in the interpretation of our findings. Second, the cross-sectional design of our investigation hampered testing causal paths. Third, parents' self-report was used to measure independent, dependent and mediating variables and our findings may have benefit from shared method variance. To avoid method variance, future research should use multiple measures (e.g., official data, prospective instruments, multi-informant data). Fourth, previous literature regarding parents' physical maltreatment risk and their psychosomatic symptoms is very limited. Our theoretical and empirical background was developed under previous research that measured history of child physical victimization in parents with a somatic disorder, as well as parents' actual physical maltreatment, rather than parents' risk of physically maltreating their offspring. Despite the fact that our findings were in line with those that measured actual physical maltreatment and those that used samples with adults with a diagnosed somatic disorder, some caution should be assumed in the interpretation of our results. Fifthly, in line with this limitation, we did not screen physical/psychosomatic disorders, since the BSI somatization scale only assesses psychosomatic symptomatology. Since this is the first study, to our knowledge, to examine the mediation effect of psychosomatic symptomatology, future research with parents with diagnosed psychosomatic disorders is encouraged.

In summary, to our knowledge, this was the first study to test in a representative community sample the association between parents' psychosomatic symptoms and their risk of offspring maltreatment. Additionally, the current study extends prior research on intergeneration transmission of child physical maltreatment by demonstrating that the association between parents' history of physical victimization and their current risk of physical maltreatment is in part mediated by parents' psychosomatic symptoms. The partial mediation effect of psychosomatic symptoms indicates that additional risk mechanisms may operate in the intergenerational continuity of child physical maltreatment. These findings provide evidence that functional, emotional and social impairments related to psychosomatic conditions may disrupt parenting practices and contribute to a heightened likelihood of occurrence of physical abusive strategies in parents that reported to be victims of more frequent physical maltreatment behaviors from a primary caregiver in childhood.

\section{Conflict of interest statement}

Diogo Lamela and Bárbara Figueiredo (co-authors of this paper) declare no actual or potential conflict of interest including any financial, personal or other relationships with other people or organizations within three years of beginning the submitted work that could inappropriately influence, or be perceived to influence, their work.

\section{Acknowledgments}

The study was supported by the Portuguese Foundation of Science and Technology through a research grant to the second author (POCTI/PSI/ 14276/1998) and a PhD fellowship to the first author (SFRH/BD/43525/ 2008). The funding agency had no role in the study's design, in the collection, analysis, and interpretation of the data, in the writing of the report or in the decision to submit the paper for publication.

\section{References}

[1] Mills R, Alati R, O'Callaghan M, Najman J, Williams G, Bor W, et al. Child abuse and neglect and cognitive function at 14 years of age: findings from a birth cohort. Pediatrics 2011;127:4-10

[2] Kim J, Cicchetti D, Rogosch F, Manly J. Child maltreatment and trajectories of personality and behavioral functioning: implications for the development of personality disorder. Dev Psychopathol 2009;21:889-912.

[3] Alink L, Cicchetti D, Kim J, Rogosch F. Longitudinal associations among child maltreatment, social functioning, and cortisol regulation. Dev Psychol 2012;48: 224-36.

[4] Lansford J, Dodge K, Pettit G, Bates J. Does physical abuse in early childhood predict substance use in adolescence and early adulthood? Child Maltreat 2010;15:190-4.

[5] Lansford J, Miller-Johnson S, Berlin L, Dodge K, Bates J, Pettit G. Early physical abuse and later violent delinquency: a prospective longitudinal study. Child Maltreat 2007; $12: 233-45$.

[6] Scott K, McLaughlin K, Smith D, Ellis P. Childhood maltreatment and DSM-IV adult mental disorders: comparison of prospective and retrospective findings. Br J Psychiatry 2012;200:469-75.

[7] Afifi T, Mota N, Dasiewicz P, MacMillan H, Sareen J. Physical punishment and mental disorders: results from a nationally representative US sample. Pediatrics 2012;130:184-92.

[8] Hager A, Runtz M. Physical and psychological maltreatment in childhood and later health problems in women: an exploratory investigation of the roles of perceived stress and coping strategies. Child Abuse Negl 2012;36:393-403.

[9] Widom C, Czaja S, Bentley T, Johnson M. A prospective investigation of physical health outcomes in abused and neglected children: new findings from a 30-year follow-up. Am J Public Health 2012;102:1135-44.

[10] Anne Lown E, Nayak M, Korcha R, Greenfield T. Child physical and sexual abuse: a comprehensive look at alcohol consumption patterns, consequences, and dependence from the National Alcohol Survey. Alcohol Clin Exp Res 2011;35:317-25. 
[11] McKinney C, Caetano R, Ramisetty-Mikler S, Nelson S. Childhood family violence and perpetration and victimization of intimate partner violence: findings from a national population-based study of couples. Ann Epidemiol 2009;19:25.

12] Thornberry T, Henry K. Intergenerational continuity in maltreatment.J Abnorm Child Psychol 2013 [in press].

[13] Cicchetti D, Rizley R. Developmental perspectives on the etiology, intergenerational transmission, and sequelae of child maltreatment. New Dir Child Adolesc Dev 1981: 31-55.

[14] Thornberry T, Knight K, Lovegrove P. Does maltreatment beget maltreatment?: a systematic review of the intergenerational literature. Trauma Violence Abuse 2012;13:135-52.

[15] Stith S, Liu T, Davies L, Boykin E, Alder M, Harris J, et al. Risk factors in child maltreatment: a meta-analytic review of the literature. Aggress Violent Behav 2009;14:13-29.

[16] Berlin L, Appleyard K, Dodge K. Intergenerational continuity in child maltreatment: mediating mechanisms and implications for prevention. Child Dev 2011;82:162-76.

[17] Kim J. Type-specific intergenerational transmission of neglectful and physically abusive parenting behaviors among young parents. Child Youth Serv Rev 2009;31:761-7.

[18] Plant D, Barker E, Waters C, Pawlby S, Pariante C. Intergenerational transmission of maltreatment and psychopathology: the role of antenatal depression. Psychol Med 2012;1:1-10.

[19] Milner JS, Thomsen C, Crouch J, Rabenhorst M, Martens P, Dyslin C, et al. Do trauma symptoms mediate the relationship between childhood physical abuse and adult child abuse risk? Child Abuse Negl 2010;34:332-44.

[20] Paúl J, Domenech L. Childhood history of abuse and child abuse potential in adolescent mothers: a longitudinal study. Child Abuse Negl 2000;24:701-13.

[21] Ornduff S, Kelsey R, Bursi C, Alpert B, Bada H. Child abuse potential in at-risk African American mothers: the role of life experience variables. Am J Orthopsychiatry 2002;72:433-44.

[22] Valentino K, Nuttall A, Comas M, Borkowski J, Akai C. Intergenerational continuity of child abuse among adolescent mothers authoritarian parenting, community violence, and race. Child Maltreat 2012;17:172-81.

[23] Pears K, Capaldi D. Intergenerational transmission of abuse: a two-generational prospective study of an at-risk sample. Child Abuse Negl 2001;25:1439-61.

[24] Singh Narang D, Contreras J. Dissociation as a mediator between child abuse history and adult abuse potential. Child Abuse Negl 2000;24:653-65.

[25] Dixon L, Browne K, Hamilton-Giachritsis C. Risk factors of parents abused as children: a mediational analysis of the intergenerational continuity of child maltreatment (part I). J Child Psychol Psychiatry 2005;46:47-57.

[26] Haviland M, Morton K, Oda K, Fraser G. Traumatic experiences, major life stressors, and self-reporting a physician-given fibromyalgia diagnosis. Psychiatry Res 2010;177:335-41.

[27] Häuser W, Kosseva M, Üceyler N, Klose P, Sommer C. Emotional, physical, and sexua abuse in fibromyalgia syndrome: a systematic review with meta-analysis. Arthritis Care Res (Hoboken) 2011;63:808-20.

[28] Davis D, Luecken L, Zautra A. Are reports of childhood abuse related to the experience of chronic pain in adulthood?: a meta-analytic review of the literature. Clin J Pain 2005;21:398-405

[29] Kotch J, Browne D, Dufort V, Winsor J. Predicting child maltreatment in the first 4 years of life from characteristics assessed in the neonatal period. Child Abuse Negl 1999;23:305-19.

[30] Salmon P, Skaife K, Rhodes J. Abuse, dissociation, and somatization in irritable bowel syndrome: towards an explanatory model. J Behav Med 2003;26:1-18.

[31] Roelofs K, Keijsers G, Hoogduin K, GÃ ̌rard W, Moene F. Childhood abuse in patients with conversion disorder. Am J Psychiatry 2002;159:1908-13.

[32] Reilly J, Baker G, Rhodes J, Salmon P. The association of sexual and physical abuse with somatization: characteristics of patients presenting with irritable bowe syndrome and non-epileptic attack disorder. Psychol Med 1999;29:399-406.

[33] Brown R, Schrag A, Trimble M. Dissociation, childhood interpersonal trauma, and family functioning in patients with somatization disorder. Am J Psychiatry 2005;162: 899-905.

[34] Milner J, Robertson K, Rogers D. Childhood history of abuse and adult child abuse potential. J Fam Violence 1990;5:15-34.

[35] Figueiredo B, Bifulco A, Paiva C, Maia Â, Fernandes E, Matos R. History of childhood abuse in Portuguese parents. Child Abuse Negl 2004;28:669-82.

[36] Milner J. Child Abuse Potential Inventory: manual. Webster, NC: Psytec; 1986.

[37] Gomes J. Validation of the Portuguese version of the Child Abuse Potential Inventory. Braga: University of Minho; 2010.

[38] Derogatis L, Melisaratos N. The Brief Symptom Inventory: an introductory report Psychol Med 1983;13:595-605

[39] Novy D, Berry M, Palmer J, Mensing C, Willey J, Bruera E. Somatic symptoms in patients with chronic non-cancer-related and cancer-related pain. J Pain Symptom Manage 2005;29:603-12.

[40] Canavarro C. Inventário de Sintomas Psicopatológicos (BSI). In: Simões M, Gonçalves M, Almeida L, editors. Testes e provas psicológicas em Portugal. Braga, Portugal: APPORT; 1999. p. 95-109.
[41] MacKinnon D, Fairchild A, Fritz M. Mediation analysis. Annu Rev Psychol 2007;58: 593-614.

[42] Baron R, Kenny D. The moderator-mediator variable distinction in social psychological research: conceptual, strategic, and statistical considerations. J Pers Soc Psychol 1986:51:1173-82.

[43] Sobel M. Asymptotic confidence intervals for indirect effects in structural equation models. In: Leinhardt S, editor. Sociological methodology. Washington, DC: American Sociological Association; 1982. p. 290-312.

[44] Hayes A. Beyond Baron and Kenny: statistical mediation analysis in the new millennium. Commun Monogr 2009;76:408-20.

[45] Preacher K, Rucker D, Hayes A. Addressing moderated mediation hypotheses: theory, methods, and prescriptions. Multivar Behav Res 2007;42:185-227.

[46] Preacher K, Hayes A. Asymptotic and resampling strategies for assessing and comparing indirect effects in multiple mediator models. Behav Res Methods 2008;40:879-91.

[47] MacKinnon D, Lockwood C, Williams J. Confidence limits for the indirect effect: distribution of the product and resampling methods. Multivar Behav Res 2004;39: 99-128.

[48] Gilbert R, Widom C, Browne K, Fergusson D, Webb E, Janson S. Burden and consequences of child maltreatment in high-income countries. Lancet 2009;373: 68-81.

[49] Appleyard K, Berlin L, Rosanbalm K, Dodge K. Preventing early child maltreatment: implications from a longitudinal study of maternal abuse history, substance use problems, and offspring victimization. Prev Sci 2011;12:139-49.

[50] Goodwin R, Hoven C, Murison R, Hotopf M. Association between childhood physical abuse and gastrointestinal disorders and migraine in adulthood. Am J Public Health 2003;93:1065-7

[51] Pereira J, Vickers K, Atkinson L, Gonzalez A, Wekerle C, Levitan R. Parenting stress mediates between maternal maltreatment history and maternal sensitivity in a community sample. Child Abuse Negl 2012;36:433-7.

[52] van Dijke A, Ford J, van der Hart O, van Son M, van der Heijden P, Bühring M. Affect dysregulation in borderline personality disorder and somatoform disorder: differentiating under-and over-regulation. J Pers Disord 2010;24:296-311.

[53] Waller E, Scheidt C. Somatoform disorders as disorders of affect regulation: a study comparing the TAS-20 with non-self-report measures of alexithymia. J Psychosom Res 2004;57:239-47.

[54] De Gucht V, Heiser W. Alexithymia and somatisation: a quantitative review of the literature. J Psychosom Res 2003;54:425-34.

[55] Francis K, Wolfe D. Cognitive and emotional differences between abusive and non-abusive fathers. Child Abuse Negl 2008;32:1127-37.

[56] Wolfe D, McIsaac C. Distinguishing between poor/dysfunctional parenting and child emotional maltreatment. Child Abuse Negl 2011;35:712-21.

[57] Shackman J, Fatani S, Camras L, Berkowitz M, Bachorowski J, Pollak S. Emotion expression among abusive mothers is associated with their children's emotion processing and problem behaviours. Cogn Emot 2010;24:1421-30.

[58] Taylor C, Guterman N, Lee S, Rathouz P. Intimate partner violence, maternal stress, nativity, and risk for maternal maltreatment of young children. Am J Public Health 2009;99:175.

[59] Hien D, Cohen L, Caldeira N, Flom P, Wasserman G. Depression and anger as risk factors underlying the relationship between maternal substance involvement and child abuse potential. Child Abuse Negl 2010;34:105-13.

[60] Landa A, Peterson B, Fallon B. Somatoform pain: a developmental theory and translational research review. Psychosom Med 2012;74:717-27.

[61] Waller E, Scheidt CE. Somatoform disorders as disorders of affect regulation: a development perspective. Int Rev Psychiatry 2006;18:13-24.

[62] Terre L, Poston W, Foreyt J, St Jeor S. Do somatic complaints predict subsequent symptoms of depression? Psychother Psychosom 2003;72:261-7.

[63] Zwaigenbaum L, Szatmari P, Boyle M, Offord D. Highly somatizing young adolescents and the risk of depression. Pediatrics 1999;103:1203-9.

[64] Güleç M, Altintaş M, İnanç L, Bezgin Ç, Koca E, Güleç H. Effects of childhood trauma on somatization in major depressive disorder: the role of alexithymia. J Affect Disord 2013;146:137-41.

[65] Vitaro F, Tremblay R. Clarifying and maximizing the usefulness of targeted preventive interventions. In: Rutter M, Bishop D, Pine D, Scott S, Stevenson J, Taylor E, Thapar A editors. Rutter's child and adolescent psychiatry. London: Blackwell Publishing; 2008. p. 989-1008.

[66] Hardt J, Rutter M. Validity of adult retrospective reports of adverse childhood experiences: review of the evidence. J Child Psychol Psychiatry 2004:45:260-73.

[67] Brewin C, Andrews B, Gotlib I. Psychopathology and early experience: a reappraisal of retrospective reports. Psychol Bull 1993;113:82-98.

[68] Maughan B, Rutter M. Retrospective reporting of childhood adversity: issues in assessing long-term recall. J Pers Disord 1997;11:19-33. 